\title{
Endoluminal appendectomy: the first description in humans for acute appendicitis
}

Appendix inversion into the cecal lumen can be demonstrated, and its endoluminal appendectomy is feasible [1]. We describe the first procedure to remove the appendix using colonoscopy during acute appendicitis presentation.

A video colonoscope (Pentax Medical, Tokyo, Japan) and a handmade doublechannel colonoscope prototype with an adapted $20 \mathrm{Fr}$ nasogastric tube were used for the colonoscopy (> Fig. 1). Shark Tooth grasping forceps (Olympus Medical Systems, Tokyo, Japan), an endoloop (Olympus), a standard diathermic snare wire loop (Boston Scientific Corp., Marlborough, Massachusetts, USA), and endoclips (Olympus) were also used. Owing to such an unconventional procedure, informed consent was obtained from the patient's wife and from his surgeon after the colonoscopic findings during the same procedure.

A 67-year-old man with transverse colostomy secondary to surgical resection of a prior obstructive sigmoid neoplasm, presented with vague lower abdominal pain and fever. Two days earlier, an ultrasonography showed an enlarged appendix. A colonoscopy was performed to investigate synchronic lesions and showed only a purulent discharge from the appendiceal orifice.

The endoloop from the attached nasogastric tube was opened and positioned close to the appendiceal orifice. The Shark Tooth grasping forceps was passed through the endoloop and gently into the appendix until tissue resistance was detected. The appendix tip was grasped and inverted back into the lumen in a single pull-through motion ( $\vee$ Video 1 ). The appendix presented with a reddish orange mucosa in its tail. A diathermic snare wire loop (Blend 1, 30 W) was then placed over the inverted appendix to cut. Another endoloop was loaded, and then endoclips were used to fix the ligating loop into position and close the ligated appendix base ( $\triangleright$ Fig.2, $>$ Video 1). No bleeding was observed.

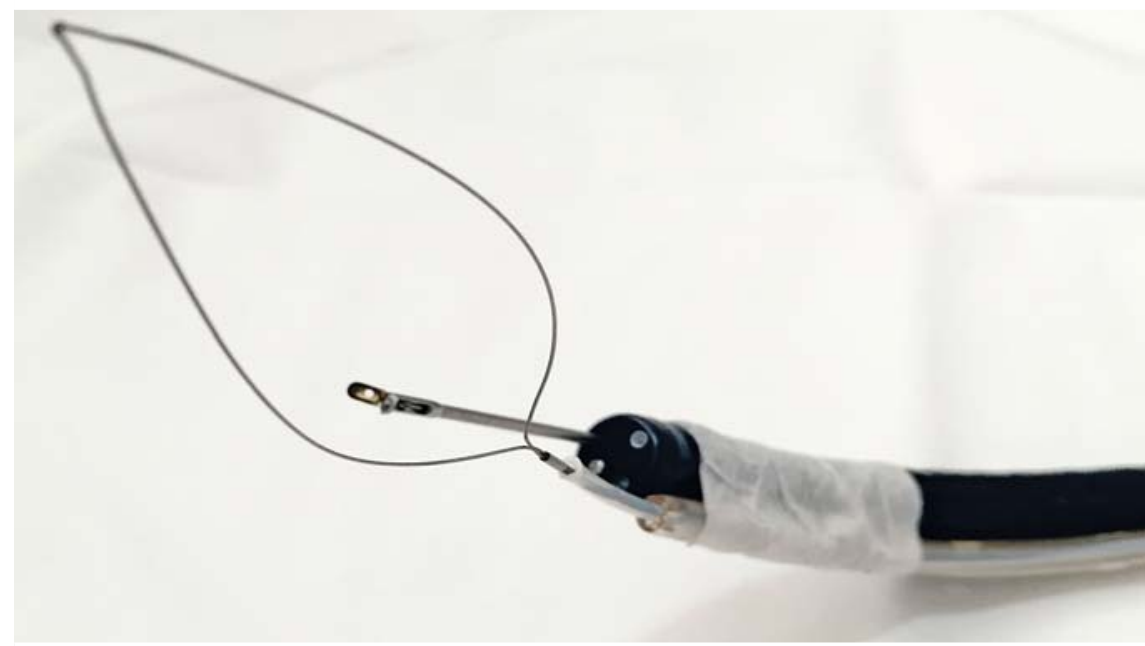

- Fig. 1 The handmade colonoscope prototype, consisting of a double-channel endoscope with Shark Tooth grasping forceps (Olympus Medical Systems, Tokyo, Japan) and a $20 \mathrm{Fr}$ nasogastric tube for endoloop passage.
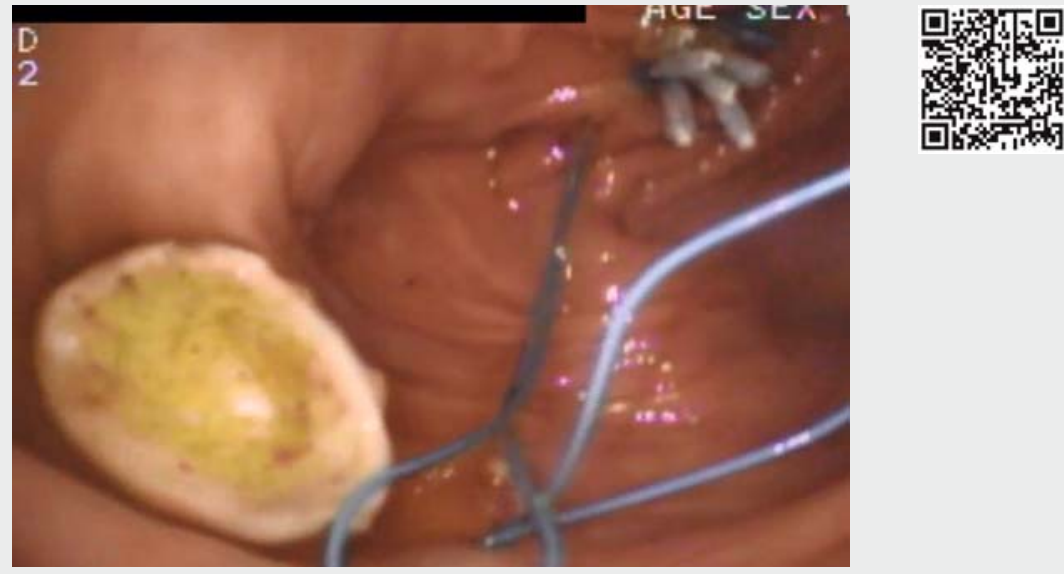

Video 1 Removal of the appendix using colonoscopy in a case of acute appendicitis. We inverted the appendix in a single pull-through motion. An endoloop was loaded before and after the appendix was resected using a diathermic snare. Pathological assessment confirmed acute appendicitis.

Pathological assessment confirmed acute appendicitis (> Fig. $\mathbf{3}$ ).

The patient experienced abdominal discomfort and low-grade fever on the first postoperative day. He received ceftriaxone $2 \mathrm{~g} /$ day and metronidazole $1.5 \mathrm{~g} /$ day for 2 days; oral diet was started on the same day. On the second postoperative day, the patient's condition improved, without any report of pain.

Endoscopy_UCTN_Code_TTT_1AQ_2A] 

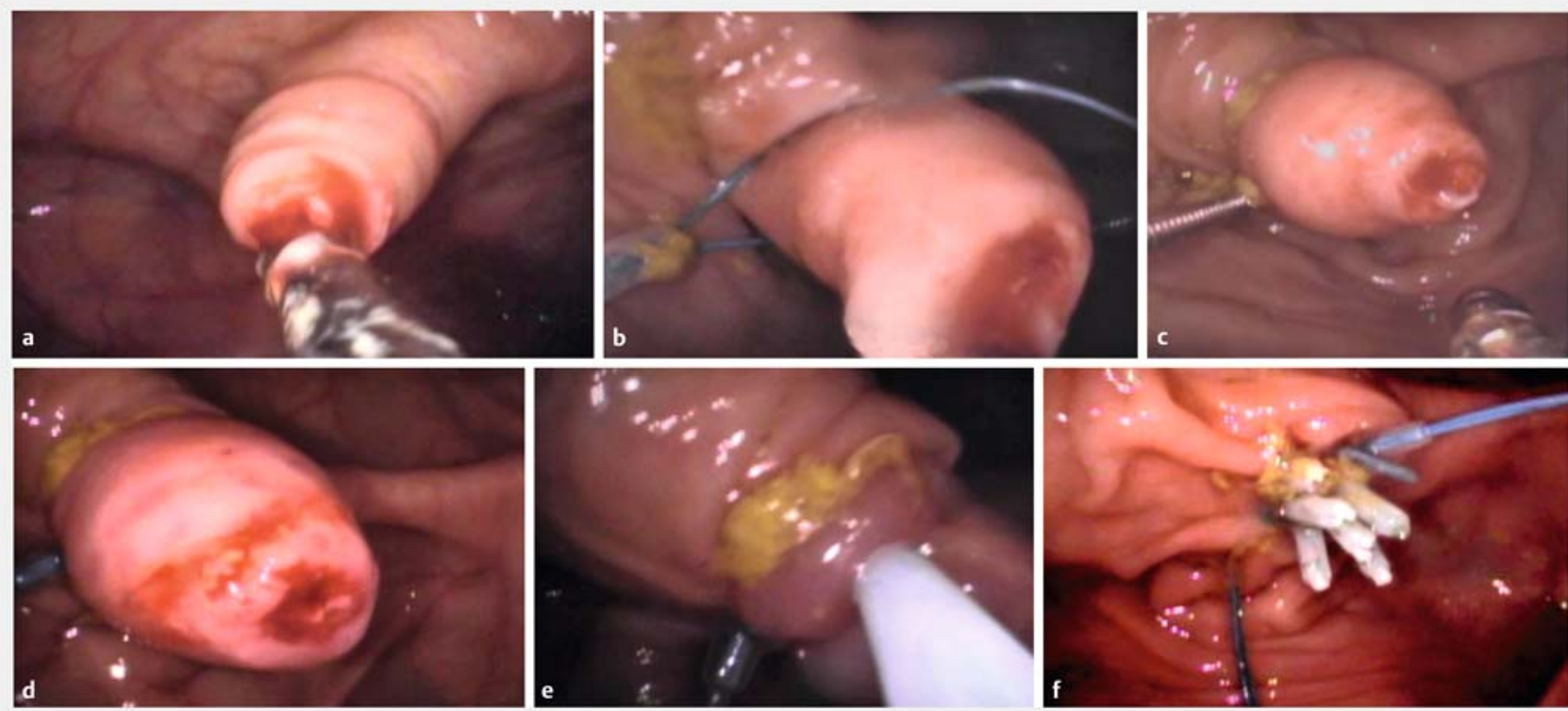

- Fig. 2 Endoluminal appendectomy - endoscopic view. a Inversion of the appendix using grasping forceps. $\mathbf{b}$ Endoloop positioning over the base of the inverted appendix. $\mathbf{c}$ Cutting the base with a snare loop.d-f The resected area of the appendix was closed using hemostatic clips.
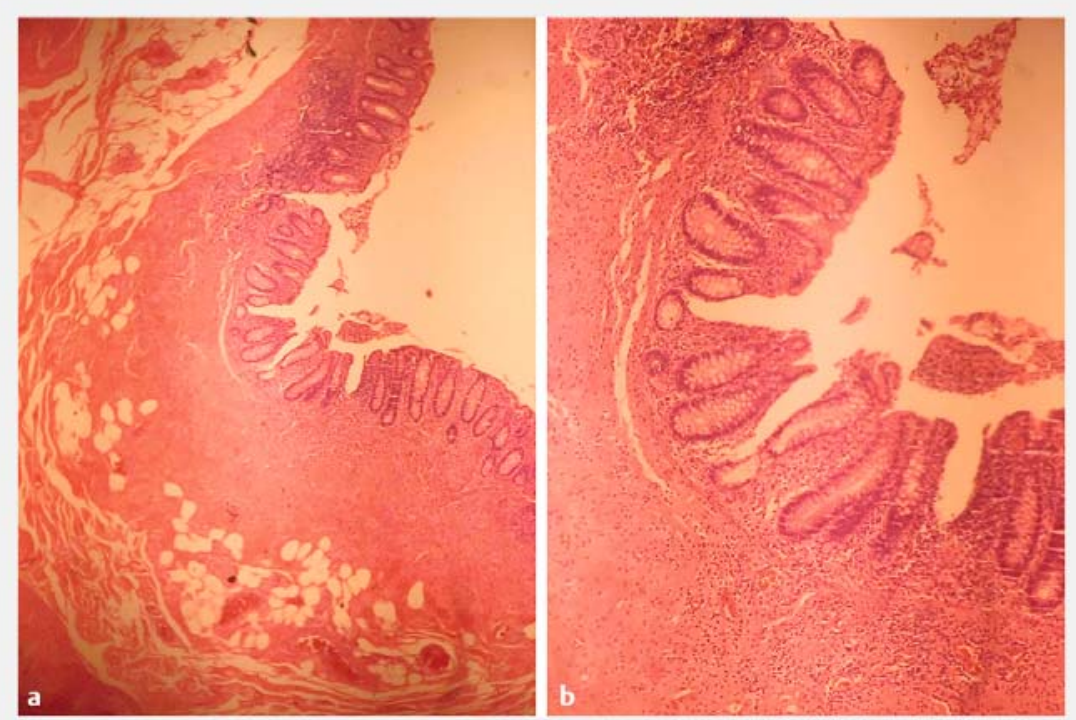

-Fig. 3 Pathological assessment showed inflammatory cells in the submucosa (hematoxylin and eosin staining).

\section{Competing interests}

None

The Authors

Everson L. A. Artifon, Ricardo Sato Uemura, Carlos Kiyoshi Furuya Júnior, Carolina Manna Santos, Diego Soares Coca, Hugo Gonçalo Guedes, José Pinhata Otoch

\section{Reference}

[1] Silberhumer GR, Birsan T, Noda W et al. Design and instrumentation of new devices for performing appendectomy at colonoscopy (with video). Gastrointest Endosc 2008; 68: 139-145

\section{Bibliography}

DOI https://doi.org/10.1055/s-0043-107611

Endoscopy 2017; 49: 609-610

(c) Georg Thieme Verlag KG

Stuttgart · New York

ISSN 0013-726X

\section{ENDOSCOPY E-VIDEOS}

https://eref.thieme.de/e-videos

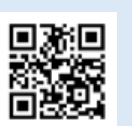

Endoscopy E-Videos is a free access online section, reporting on interesting cases and new

techniques in gastroenterological endoscopy. All papers include a high quality video and all contributions are freely accessible online.

Everson L. A. Artifon, MD, PhD

Division of Gastrointestinal Endoscopy, Hospital Ana Costa, Santos, Brazil, Guimarães Passos Street 260/121, São Paulo - SP 04107-030, Brazil eartifon@hotmail.com 